This item was submitted to Loughborough's Research Repository by the author.

Items in Figshare are protected by copyright, with all rights reserved, unless otherwise indicated.

\title{
Different paths to consensus? The impact of need for closure on model- supported group conflict management
}

\author{
PLEASE CITE THE PUBLISHED VERSION
}

http://dx.doi.org/10.1016/j.ejor.2015.06.056

PUBLISHER

(C) Elsevier

VERSION

AM (Accepted Manuscript)

\section{PUBLISHER STATEMENT}

This work is made available according to the conditions of the Creative Commons Attribution-NonCommercialNoDerivatives 4.0 International (CC BY-NC-ND 4.0) licence. Full details of this licence are available at: https://creativecommons.org/licenses/by-nc-nd/4.0/

\section{LICENCE}

CC BY-NC-ND 4.0

\section{REPOSITORY RECORD}

Franco, Alberto, Etienne A.J.A. Rouwette, and Hubert Korzilius. 2015. "Different Paths to Consensus? the Impact of Need for Closure on Model-supported Group Conflict Management". Loughborough University. https://hdl.handle.net/2134/18942. 


\title{
Different paths to consensus? The impact of need for closure on model-supported group conflict management
}

\author{
L. Alberto Franco ${ }^{\mathrm{a} 1}$, Etiënne A.J.A. Rouwette ${ }^{\mathrm{b}}$, Hubert Korzilius ${ }^{\mathrm{b}}$ \\ a School of Business and Economics, Loughborough University, Leicestershire LE11 3TU, UK \\ ${ }^{\mathrm{b}}$ Institute for Management Research, Radboud University Nijmegen, Nijmegen, $6500 \mathrm{HK}$, The \\ Netherlands
}

\begin{abstract}
Empirical evidence on how cognitive factors impact the effectiveness of model-supported group decision making is lacking. This study reports on an experiment on the effects of need for closure, defined as a desire for definite knowledge on some issue and the eschewal of ambiguity. The study was conducted with over 40 postgraduate student groups. A quantitative analysis shows that compared to groups low in need for closure, groups high in need for closure experienced less conflict when using Value-Focused Thinking to make a budget allocation decision. Furthermore, low need for closure groups used the model to surface conflict and engaged in open discussions to come to an agreement. By contrast, high need for closure groups suppressed conflict and used the model to put boundaries on the discussion. Interestingly, both groups achieve similar levels of consensus, and high need for closure groups are more satisfied than low need for closure groups. A qualitative analysis of a subset of groups reveals that in high need for closure groups only a few participants control the model building process, and final decisions are not based on the model but on simpler tools. The findings highlight the need to account for the effects of cognitive factors when designing and deploying modelbased support for practical interventions.
\end{abstract}

Keywords: behavioural OR, need for closure, decision processes, conflict management, model-based group support.

\section{Introduction}

Group decision making is a common practice in organisations today. The need for group decision making arises because a single individual's perspective, knowledge, or information processing capacity are too limited to cope with the organisational challenges brought about by the fast changing and interconnected world of the $21^{\text {st }}$ century. For a group decision making process to be effective, group members should be able to surface, share and transform their different perspectives about the decision problem being considered. This can be challenging, but there is a wide variety of model-based group approaches developed within the operational research and systems fields to support this process (Morton et al., 2003). Located mainly within the European soft OR tradition, these approaches share a focus on supporting negotiation within the group, using visual models and 'on-the-spot' modelbased analysis to enable group members to surface their different perspectives, resolve their differences, and achieve a negotiated agreement about the way forward (Ackermann, 2012; Franco and Montibeller, 2010; Mingers, 2011). Illustrative examples of well-established model-based support approaches include Cognitive Mapping and SODA (Ackermann and Eden, 2010; Eden, 1988), Strategic Choice Approach (Friend and Hickling, 2005), ValueFocused Thinking (Keeney, 1996), Decision Conferencing (Phillips, 2007) and Group Model Building (Richardson and Andersen, 1995; Vennix, 1996, 1999).

To date, empirical research on model-supported group decision making has typically examined model-based interventions as complex global phenomena, mainly through case

\footnotetext{
${ }^{1}$ Corresponding author telephone +44 (0)1509 228 004; email: $\underline{\text { l.a.franco@lboro.ac.uk }}$
} 
Cite as: Franco, LA, Rouwette, EAJA, Korzilus, H. Different paths to consensus? The impact of need for closure on model-supported group conflict management. European Journal of Operational Research (2015), http://dx.doi.org/10.1016/j.ejor.2015.06.056

studies or action research methodologies (Eden, 1995; Franco and Montibeller, 2010). While such a research focus has produced useful insights (e.g. Franco and Lord, 2011; Rouwette et al., 2011; Schilling et al., 2007; Shaw et al., 2003; White, 2009), scant attention has been paid to examining contingency factors other than the organisational context within which the group is located (e.g. Franco, 2009; Montibeller et al., 2009). In particular, there is little understanding of how cognitive factors influence the effectiveness of model-supported group decision making. In line with recent calls for developing the behavioural agenda within OR in this journal (Hamalainen et al., 2013), our paper contributes to a developing body of work concerned with the cognitive dimension of model use within groups (e.g. Ackermann and Eden, 2011; Franco and Meadows, 2007; Rouwette et al., 2011). Specifically, we explore the potential impact of group members' differences in need for closure (Kruglanski et al., 2006; Kruglanski and Webster, 1996) on the effectiveness of model-supported group processes, with particular emphasis on conflict management processes. Our study intends to increase the understanding of the role of cognition in model-based interaction, and shed light onto the possible ways in which group members approach a model-supported decision task.

In the remainder of this paper we discuss the nature of model-supported group decision making from a conflict management perspective, introduce the need for closure construct and our research questions, discuss the results and limitations of our analysis, and offer some conclusions and future research directions.

\section{Group decision making, conflict management and model-based support}

Group decision making involves purposefully bringing together a group of individuals whose knowledge, expertise or interests are considered relevant to the decision context under consideration. The effectiveness of group decision-making is contingent upon the group's ability to: (1) surface and share their knowledge and initial interpretations of the key issues constituting the decision context; and, (2) identify commonalities in views, form a consolidated perspective of the issues or options, and work out a resolution that takes various positions into account and is both desirable and feasible (Eden and Ackermann, 2010). The first condition is needed to deter the group from falling into potential traps associated with groupthink - namely, conformity to group values and ethics leading, among others, to the suppression of deviant opinions (Janis, 1972) - and 'type III error' - namely, solving the wrong problem (Mitroff and Ernshoff, 1974). The second condition reduces the chances of a never-ending increase in views and interpretations that is likely to lead to information overload.

These two conditions have been associated with what is known as the differentiation and integration phases of group decision making, respectively (Folger et al., 1996). If either phase of differentiation or integration gets truncated or ineffectively managed, a less satisfactory outcome is likely to follow. To take advantage of the benefits of effective differentiation and integration, groups must be able to manage conflict successfully. Conflict arises because group members are likely to have different opinions regarding the issues framing the decision they face, and on the direction to take. Furthermore, the existence of social pressures and power differences within the group will influence members' exchanges and analysis of the decision context (Eden and Ackermann, 2010). Consequently, groups engaged in decision making are likely to experience various levels of conflict and how they manage it determines to a great extent their effectiveness.

The literature describes different patterns of conflict management, each differing in their degree of 'confrontiveness', or the ability of groups to surface conflict manifest in their competing perspectives and deal with their differences constructively (De Dreu and Weingart, 2003; De Wit et al., 2012; Folger et al., 1996). The least confrontive strategy is to avoid the conflict or ignore it altogether. In this case group members never surface their 
Cite as: Franco, LA, Rouwette, EAJA, Korzilus, H. Different paths to consensus? The impact of need for closure on model-supported group conflict management. European Journal of Operational Research (2015), http://dx.doi.org/10.1016/j.ejor.2015.06.056

differences and maintain a false consensus where some issues are never raised and some interests are not satisfied. Next on the scale is to surface the conflict, but resolution entails one particular position prevailing at the expense of others (i.e. a 'win-lose' approach). This is confrontive in the sense that group members acknowledge the presence of the conflict. However, they do not fully confront their differences if they force one party to accept a solution contrary to their initial preferences. Finally, full confrontation means that the group acknowledges the conflict and tries for a solution acceptable to all members.

Some guidelines for effective conflict management are suggested by the literature. These include creating a cooperative climate (Alper et al., 2000), focussing on the problem rather than on people (Fisher and Ury, 1991), and considering a range of options before converging on a specific solution (Nutt, 2002, 2008). One particular approach specifically designed to help groups manage conflict through effective negotiation is model-based group support (Morton et al., 2003). Developed within the operational research and systems fields, and in contrast to technology-driven forms of support such as computer-supported systems (DeSanctis and Gallupe, 1987; Jessop and Valacich, 1993), model-based support facilitates differentiation of views and positions by providing a medium and a set of procedures for group interaction. The medium is the model that provides group members with a shareable and easily recognised artefact around which they can interact; the set of procedures comprises rules for collating and coding group members' views, and structured group processes designed to steer members away from behaviours that would inhibit effective group participation. The different model-based support approaches are most easily distinguished on the basis of the medium (type of model) they use. For example, Strategic Options Development and Analysis (Ackermann and Eden, 2010) uses means-ends networks of argumentation; Soft Systems Methodology (Checkland and Poulter, 2006) relies upon building rich pictures of the problem situation and models of a purposeful 'activity' system; the Strategic Choice Approach (Friend and Hickling, 2005) works with decision graphs; and, Group Model Building captures the structure of a problem in the form of a causal loop diagram or stock and flow model (Vennix, 1996). Procedures for group interaction are similar across approaches (Franco and Montibeller, 2010; Phillips and Phillips, 1993).

In the differentiation phase, these processes may include brainstorming or one of its variants. Model-based support is also designed to enable the integration of different views. Modelbased interaction and analysis is intended to encourage open discussion regarding different interpretations of cause-and-effect relations, which helps group members appreciate the assumptions and beliefs of others and reflect on their own understanding of the decision context. Model-based interaction and analysis is thus the basis upon which the group is able to build and test alternative interpretations of the decision context, which in turn serves to negotiate shared meanings and common interests. Additionally, procedures used in modelbased support steer groups away from negative behaviours such as suppressing differences in viewpoints, one side giving in, or a few group members covertly manipulating others into submission. We posit that effective conflict management is facilitated via model-based support because model-based interaction and analysis force members to acknowledge the conflict that results from having different interpretations and interests, and encourage them to openly discuss their differences so that a negotiated agreement can be reached. In others words, model-based support enables the high level of confrontiveness that is required to manage conflict effectively (Folger et al., 1996).

In the next section, we review group composition from a cognitive perspective and introduce 'need for closure' (Kruglanski et al., 2006; Kruglanski and Webster, 1996) as a relevant contingency factor for the study of model-supported group decision making. We then articulate research questions concerning the potential implications of a heightened need for closure for the effectiveness of model-supported conflict management processes and outcomes. 
Cite as: Franco, LA, Rouwette, EAJA, Korzilus, H. Different paths to consensus? The impact of need for closure on model-supported group conflict management. European Journal of Operational Research (2015), http://dx.doi.org/10.1016/j.ejor.2015.06.056

\section{Group composition, need for closure and model-supported conflict management}

Along with group size (Hare, 1981; Thomas and Fink, 1963) and stage of development (Gersick, 1988, 1989; W. Watson et al., 1991), group composition is recognised as a key factor in explaining the benefits and dangers of group decisions. Research on group composition has considered a number of demographical and organisational dimensions (e.g. Jackson et al., 2003; Williams and O'Reilly, 1998), generally reporting that group heterogeneity increases the quality of decision making provided that group problems such as subgroup biases and interpersonal conflict (e.g. Jehn et al., 1999; Pelled et al., 1999; van Knippenberg et al., 2004) are avoided. Research on group composition has also considered the role and impact of cognition in group decision making. Cognition refers to processes of knowledge acquisition and processing, in which representations such as symbols, frames, schemas and goals play a central role (Gardner, 1987). Cognitive style (S. Armstrong et al., 2012) refers to recurrent patterns in mental activities, or the idea that different people acquire and process knowledge differently. Research indicates that group members' cognitive styles may improve or impede group decision making.

For example, the study by Armstrong and Priola (2001) indicated that the impact of group members' cognitive styles on the decision making process depended on the decision context: homogeneous intuitive teams initiated more task-oriented behaviours in unstructured and organic rather than well-structured and mechanistic environments. Volkema and Gorman (1998) found that individual differences in information processing moderate the effect of problem formulation on group performance: heterogeneous groups that employed explicit governing objectives (discussions and decisions on objectives) significantly outperformed all others. However, cognitive-based composition did not generally predict group decision making processes and outcomes. In Beaty et al's (2001) study, a job setting presented a strong situation when a supervisor's remarks or the company's performance guidelines created a uniform perception of desired performance behaviours among employees. In contrast, the weak situation was perceived as ambiguous because of inconsistent or infrequent cues. In the weak situation, personality variables such as extraversion had a stronger impact on intended behaviour than in the strong situation. Despite these mixed results, the cognitive dimension of group composition offers the potentially most useful avenue for the study of model-supported group decision making. Model-supported group decision making occasions are atypical events that entail the removal of group members from their work environments and everyday routines, to engage in novel tasks in unfamiliar social and physical settings. They provide few dispositional cues to participants regarding appropriate behaviours, and thus constitute 'weak' situations. A considerable volume of basic theory and research shows that cognitive factors and personality traits exert strong influences on behaviour in such weak situations (Beaty et al., 2001; de Kwaadsteniet et al., 2006; Snyder and Ickes, 1985).

A pertinent line of theory and research on the cognitive factors affecting group decision making has been proposed by Kruglanski and his colleagues (e.g. Kruglanski et al., 2006). This research extends earlier work on the effects of 'need for closure' (NFC) among individuals to the group level. NFC is defined as a desire for definite knowledge on some issue and the eschewal of confusion and ambiguity (Kruglanski, 1989, 1990, 2004; Kruglanski et al., 2009). NFC is presumed to exert its effects on individuals via two general tendencies: the urgency tendency, reflecting the inclination to attain closure as quickly as possible, and the permanence tendency, reflecting the tendency to maintain it for as long as possible. Jointly, the urgency and permanence tendencies may produce the inclinations to 'seize' and then 'freeze' (Kruglanski and Webster, 1996) on early judgmental cues. 
Cite as: Franco, LA, Rouwette, EAJA, Korzilus, H. Different paths to consensus? The impact of need for closure on model-supported group conflict management. European Journal of Operational Research (2015), http://dx.doi.org/10.1016/j.ejor.2015.06.056

Kruglanski (1989) argues that NFC represents a relatively stable dimension of individual differences, but also a situationally inducible state (e.g. via time pressure) influenced by the perceived benefits of closure (or costs of lacking it). For example, stressful group work conditions tend to increase this need, which has a number of consequences for information exchange and utilization. Groups experiencing a heightened NFC exhibit a stronger desire for uniformity of opinion or preference (Kruglanski et al., 1993). Unless group members already have very strongly held preferences (in which case the freezing inclination can lead to a reduced readiness to yield to others), such uniformity can be achieved through stronger attempts to influence opinion deviates and/or a greater readiness to yield to others. Both processes should encourage centralization of power and influence in a few influential group members, manifest by greater conversational and power asymmetry in the group (De Grada et al., 1999) and communication patterns centralized on the more powerful members (Pierro et al., 2003). Once a clear group position or solution has been achieved, a heightened NFC prompts (Kruglanski and Webster, 1991): (1) stronger tendencies for group members to support that position; and (2) pressures to accept those that conform and reject those that deviate from that position. In summary, Kruglanski has shown that individual differences or stressful conditions tend to result in a 'closing of the group mind', namely, an aversion to unpopular options, an acceptance of autocratic leadership and extant group norms. The validity of these arguments has been demonstrated by empirical research based on the manipulation of NFC in groups via group composition (e.g. Chirumbolo et al., 2004; De Grada et al., 1999; Kruglanski and Webster, 1991). Closing of the group mind may lead to 'group centrism' (Kruglanski et al., 2006), a phenomenon characterised by the degree to which group members strive to maintain a firm, consensually supported, 'shared reality' (Hardin and Higgins, 1996) unperturbed by dissent and disagreements. Group centrism constitutes a key problem in the ability of groups to manage conflict effectively, as it involves group members exerting uniformity pressures on each other to arrive at speedy consensus (De Grada et al., 1999). Furthermore, the quest for uniformity under heightened NFC tends to lead to intolerance to ambiguity (Kruglanski, 1989, 1990; Kruglanski and Webster, 1996) and a rejection of opinion deviates (Kruglanski and Webster, 1991; Webster and Kruglanski, 1994). Increased ambiguity can result from surfacing conflict and opposition regarding competing interpretations that may impede the arrival at consensus, thereby reducing the group's ability to create a shared reality and reach closure. In short, premature group consensus and conformity pressure may elicit a 'groupthink' type of process, making a group avoid conflict and resulting in an incomplete consideration of options (Chirumbolo et al., 2004; Park, 2000; Turner and Pratkanis, 1988).

Implicit in the model-based group support tradition is the premise that model-based interaction and analysis facilitates effective conflict management by enabling group members to surface and acknowledge the conflict, and deal with it constructively via open discussion rather than avoidance or competition. Because groups exhibiting a heightened NFC are less likely to surface conflict and opposition, or attempt to resolve it by tabling or capitulation via uniformity pressures (De Grada et al., 1999) and rejection of opinion deviates (Kruglanski and Webster, 1991; Webster and Kruglanski, 1994), an interesting issue to explore is whether a heightened NFC in a group can affect the effectiveness of model-supported conflict management. Visual models (e.g. a causal map, a causal loop diagram, a means-ends objectives network) may reduce interpersonal conflict by enabling group members to focus on the issues rather than personal turf-wars, as well as help to surface a conflict and deal with it in a time-efficient manner. Models may offer groups high in NFC a means to better handle ambiguity and a way to incorporate the opinion of deviates so that a consensus view can be found. On the other hand, the use of models may require significant effort and time. Given than high NFC is typically associated with the need to arrive at speedy consensus (De Grada et al., 1999), model-based support may make high NFC groups (compared to low NFC groups) more or less satisfied with the decision making process. 
Cite as: Franco, LA, Rouwette, EAJA, Korzilus, H. Different paths to consensus? The impact of need for closure on model-supported group conflict management. European Journal of Operational Research (2015), http://dx.doi.org/10.1016/j.ejor.2015.06.056

In the next sections we present our empirical analysis of the possible effects of the behavioural tendencies associated with the NFC construct on model-supported group conflict management processes and outcomes.

\section{Conceptual model, research questions and methodology}

Figure 1 illustrates the conceptual model used to frame our study. The model-supported conflict management process is expected to be influenced by the level of NFC experienced by the group. In turn, model-supported conflict management processes should permit explanations about the quality of the group outcomes. The conceptual model shown in Figure 1 helps to articulate our key questions as follows:

\section{PLACE FIGURE 1 ABOUT HERE}

(1) How does NFC in a group influence conflict management in a model-supported process? Our aim here is to examine on the one hand whether high (compared to low) NFC groups bring fewer issues out into the open, or in other words experience a lower number of conflicts. We also assess whether high NFC groups resolve conflicts that do arise in less confrontive ways, using win-lose rather than open conflict management processes.

(2) What is the relationship between conflict management and decision quality? A significant body of conflict management research has produced compelling evidence that the higher the confrontiveness of the conflict management process, the higher the consensus in the group, irrespective of whether the process is supported or not (e.g. Eisenhardt et al., 1997; Folger et al., 1996; Garvin and Roberto, 2001; Poole and Dobosh, 2010; Sambamurthy and Poole, 1992a) - but see (De Dreu and Weingart, 2003). Our focus here is thus to examine whether this relationship also holds in a modelsupported environment. Furthermore, because high confrontiveness reflects positive behaviours for tackling conflict (e.g. open discussion, collaborative problem solving, negotiation, accommodation), we would expect that group members engaging in these behaviours exhibit more consensus change, more satisfaction with their decision making process, achieve a greater focus of group member behaviour, and perceive a higher quality of recommendations.

(3) To what extent does conflict management mediate the relation between NFC in a group and decision quality? If they are to complete the differentiation and integration phases of decision making successfully, groups need to manage conflict effectively. Conflicts need to be surfaced and dealt with constructively if all information is to be integrated in the group's final decision (De Dreu and Weingart, 2003; Folger et al., 1996).

We used a classroom experiment to explore these three research questions. Details of the experiment are given next. We then turn to the quantitative analysis of results, followed by a qualitative analysis of group decision processes.

\subsection{Participants, task and manipulation}

The participants were postgraduate students enrolled in model-based modules at a large business school in the United Kingdom (35 groups) and the Netherlands (eight groups). Students had a variety of nationalities. Data were gathered from 2008 to 2012, drawing on teaching cohorts from master in business administration (MBA) and specialist masters (MSc) programmes. Students participated in the experimental task as part of a wider set of module learning activities. Using model-based approaches to support decision making was part of an assessed piece of coursework, which implied that participants had an interest in completing 
Cite as: Franco, LA, Rouwette, EAJA, Korzilus, H. Different paths to consensus? The impact of need for closure on model-supported group conflict management. European Journal of Operational Research (2015), http://dx.doi.org/10.1016/j.ejor.2015.06.056

the task to the best of their ability. Analysis of the experiment videotapes (see discussion of procedures below), revealed that the groups took the task seriously, participated in it with high levels of enthusiasm, and used the model-based support approach to the extent required for exploring effects. Furthermore, groups worked together on other (non-assessed) designed class group tasks before and after the experiment, meaning they had a (albeit limited) history of prior interaction and anticipated further interaction beyond the experiment.

Although it is possible to manipulate NFC during an experiment (for example, via time pressure or increased noise), restrictions imposed by module teaching objectives meant that this was not possible. Instead, we assessed participants' innate dispositions regarding NFC to design the experimental treatment condition. One week prior to the module, participants completed a battery of instruments that included the NFC scale developed by Kruglanski and his colleagues (Kruglanski et al., 1993; Webster and Kruglanski, 1994). The original scale consists of 42 items that tap one's dispositional (rather than situational) NFC as a whole as well as five subscales. In our study we use a scale of 37 items, resulting from the deletion of four items from the original 42-item scale as suggested by Mannetti, Pierro, Kruglanski, Taris, \& Bezinovic (2002), along with the substitution of the seven items of the original Decisiveness subscale by six new items of the same subscale proposed by Roets \& Van Hiel (2007). The final five subscales are Preference for Order (e.g. 'I think that having clear rules and order at work is essential for success'; 8 items); Preference for Predictability (e.g. 'when dining out, I like to go to places where I have been before so that I know what to expect'; 8 items); Discomfort with Ambiguity (e.g. 'I don't like situations that are uncertain'; 8 items); Closed-Mindedness (e.g. 'I feel irritated when one person disagrees with what everyone else in a group believes'; 7 items); and, Decisiveness (e.g. 'when I have made a decision, I feel relieved'; 6 items). Cronbach's alpha for the complete scale of 37 items was $.87(n=166)$. For individual participants the median score on NFC is 121 . Groups with a mean score equal to or above 121 were classified as high NFC groups; groups below the median as showing a low disposition on this need, a common procedure in NFC-related research. The initial data set consisted of 43 groups. Three groups were removed from the dataset because of too low initial conflict (see below). The sample used in this study includes a total of 82 participants low on NFC, who were randomly assigned to 19 groups, forming the low NFC condition. Similarly, 87 participants high on NFC were randomly assigned to 21 groups, making up the high NFC condition.

All groups worked on the Foundation Task developed by Watson, DeSanctis, and Poole (1988), which asks participants to allocate a fixed amount of money among six competing projects that have requested funds from a philanthropic foundation. Conflict arises because group members have varying preference structures, which results in different allocation patterns. The projects participants can fund are designed to appeal to a set of basic human values (Allport et al., 1970): theoretical (purchase additional volumes for the community's library system); economic (create a tourism bureau to attract tourism to the community); aesthetic (purchase art for display in the community's art gallery); social (establish a community arts program featuring art, music, and dance programs for children and adults); political (purchase a new computer system for the county government in order to hold local taxes constant); and religious (establish an additional shelter for the homeless in the community).

\subsection{Model-based support}

To support the completion of the task, participants were asked to use Keeney's (1992, 1996, 2012) Value-Focused Thinking (VFT) approach, which is designed to help individuals or groups surface and articulate a wide variety of concerns (e.g. values, interests) relevant to a particular decision context. A key modelling activity in the VFT approach is to rephrase each concern into an objective, and distinguish 'means' objectives from 'fundamental' objectives via cause-and-effect relations. Central to Keeney's approach is the idea that when faced with 
Cite as: Franco, LA, Rouwette, EAJA, Korzilus, H. Different paths to consensus? The impact of need for closure on model-supported group conflict management. European Journal of Operational Research (2015), http://dx.doi.org/10.1016/j.ejor.2015.06.056

several options, choice should be based on the most fundamental of objectives relevant to the decision context. An objective is considered a means objective if it helps better achieve some other high level objective. If the objective represents something important in its own right, then it is a fundamental objective (see also discussion of the notion of 'goals' in Eden and Ackermann, 2013). The main output of the modelling process is a map of linked objectives, which can then be used to inform the group's decision.

The objectives map, together with the analyses that it helps to generate, provided the main mechanism for group interaction. All groups were given training and a modelling process script that was consistent with VFT principles. They were also provided with flipcharts put up on the wall and laid out to provide space for building the objectives map, together with pens, large Post-it ${ }^{\mathrm{TM}}$ notes and a whiteboard.

\subsection{Procedures}

The experimental procedure was as follows:

a) Participants read the task background information and individually allocated funds to six projects requesting support from a philanthropic trust. (Individual allocations were used to calculate pre-meeting consensus - see below.)

b) Participants received training in applying the VFT approach for 45 minutes. Training materials on VFT were tested and refined through several iterations of teaching modelbased modules prior to data collection.

c) Participants worked together as a self-facilitated group to use the VFT approach to develop an 'objectives map' relevant to the funding decision context. They were instructed to use the map (i.e. the model) to inform their fund allocation decision, and given an hour to arrive at a recommendation that had to be acceptable to all group members. Each group discussion was recorded on audio- and video-taped. (Written permission was granted prior to the experiment.)

d) Participants filled out a post-meeting questionnaire that asked them to re-evaluate individually the six projects requesting funding in light of their group discussion, and individually re-allocated funds to the six projects. (These individual allocations were used to calculate post-meeting consensus -see below.) In addition, the post-meeting questionnaire included items to measure their satisfaction with the group process, focus of group member behaviour and perception of the quality of recommendations.

\subsection{Measurement of pre-meeting consensus}

Groups approach a decision-making situation with a certain level of existing conflict in their interpretations about the issues constituting the decision context. The level of existing conflict is brought about by a combination of task and group characteristics. Tasks that are ill-structured or that are open ended with no optimal answer increase the degree of equivocality surrounding the issues and lead group members to formulate a divergent array of interpretations (Daft and Lengel, 1986). Higher amounts of equivocality result in high conflict potential due to greater divergence in the initial interpretations formulated by group members. We thus measured conflict potential due to task characteristics by assessing the degree of pre-meeting consensus with the method developed by Spillman, Spillman and Bezdek (1980). This method produces a consensus measure ranging from 0 (no agreement) to 1.0 (perfect agreement). Three groups with a pre-meeting consensus level higher than .50 were considered to be too low on potential conflict and removed from the dataset. Sambamurthy and Poole's study on Electronic Meeting Systems excludes groups with initial consensus higher than .40 (Sambamurthy and Poole, 1992: 240); we use .50 as a threshold in order to keep our dataset as large as possible while still ensuring an adequate level of initial conflict. Nijstad and De Dreu (2012) provide a theoretical rationale for the relation between initial conflict and decision making process: the confrontation with group members that have divergent preferences will undermine a participant's confidence in her own preferences, 
Cite as: Franco, LA, Rouwette, EAJA, Korzilus, H. Different paths to consensus? The impact of need for closure on model-supported group conflict management. European Journal of Operational Research (2015), http://dx.doi.org/10.1016/j.ejor.2015.06.056

because it is not shared by others. This will in turn raise epistemic motivation and increase the desire to search and process information.

\subsection{Measurement of conflict management}

The conflict management process was assessed using the Group Working Relationships Coding Scheme developed by Poole and his colleagues (Poole, 1983; Poole and Roth, 1989). The Group Working Relations Coding System (GWRCS) is based on direct observation of short segments (30 seconds) of group interaction. Segments were coded to describe seven different types of global interaction patterns that indicate various degrees of confrontiveness during the segment - see Sambamurthy and Poole (1992a) for an application. Poole and colleagues posit that quality of conflict management depends on both the extent of surfacing conflict and the way in which conflict is resolved. The lowest level of confrontiveness namely, failure to surface conflict- is indicated by group interaction coded as Integration (INT) or Focused Work (FW) periods. During INT periods the group is not task-focused, and members display positive socio-emotional behaviour such as joking or going off on a tangent. In FW periods groups are task-focused and do not disagree with one another, as in brainstorming. A somewhat higher level of confrontiveness is indicated by periods coded as Critical Work (CW), in which differences surface but no opposing sides are formed relative to an issue, and differentiation is dealt with in an implicit manner. Still more confrontive are periods classified as Opposition (OPP), during which group members acknowledge and surface conflicts. When faced with opposition, the group can choose among three approaches to manage the conflict. Groups that deal with conflict through Capitulation (CAP) or Tabling (TAB) acknowledge their conflicts but do not confront them in the most constructive manner. The most confrontive method of conflict management occurs when group members surface opposition and then deal with it through Open Discussion (OD). In this case, conflict is managed through negotiation or collaborative problem-solving in which all parties' concerns are addressed. Hence, the GWRCS enables the distinction of low confrontiveness (FW, INT), moderate confrontiveness (CW), moderately high confrontiveness (OPP followed by CAP or $\mathrm{TAB}$ ), and high confrontiveness (OPP followed by OD).

To prepare the material for coding, about 43 hours of video recordings were transcribed in full. Coding was done by two research assistants on the basis of the video recordings and transcripts. The first research assistant was trained by the first and second authors, obtaining Kappa interrater reliabilities of $.83, .79$, and .68. The second research assistant was trained by the second author, obtaining a Kappa interrater reliability of .71. Average Kappa is .75 which according to Fleiss (1981) is rated as good to excellent. In the main, differences between coders were due to different interpretations of CW and FW codes. The first research assistant coded 35 of 43 groups; the second coded the remaining eight groups. Both coded about the same number of high and low NFC groups. Both coders were neither aware of the research questions nor of the classification of groups as high nor low on NFC.

\subsection{Measurement of decision quality}

Decision quality was assessed by measuring four variables concerning group work: consensus change, satisfaction with the decision process, perceived quality of recommendations, and focus of group behaviour. Similarly to pre-meeting consensus, postmeeting consensus was assessed using the method developed by Spillman et al. (1980). Consensus change is calculated as: consensus post - consensus pre. A positive (negative) number means an increase (decrease) in group consensus from pre to post.

Self-reported data was obtained through validated instruments. Satisfaction with the decision process was measured with five items. Items were measured on 5-point semantic differentials, anchored by efficient - inefficient, coordinated - uncoordinated, fair - unfair, confusing - understandable and satisfying - dissatisfying (Green and Taber, 1980; Cronbach's alpha $=.73)$. 
Cite as: Franco, LA, Rouwette, EAJA, Korzilus, H. Different paths to consensus? The impact of need for closure on model-supported group conflict management. European Journal of Operational Research (2015), http://dx.doi.org/10.1016/j.ejor.2015.06.056

Perceived quality of group recommendations was measured with eight items. Items were measured on 7-point semantic differentials and addressed the discussion's overall quality (poor - good), effectiveness (effective - ineffective), outcome (unsatisfactory - satisfactory), execution (competently executed - incompetently executed), issues explored in the discussion (trivial - substantial), content (carefully developed - carelessly developed), manner in which participants examined issues (nonconstructive - constructive) and the group's movement towards reaching a conclusion (significant - insignificant) (Gouran et al., 1978; Cronbach's alpha $=.84$ ).

Finally, eight items addressed focus of group member behaviour (Gouran et al., 1978; Cronbach's alpha $=.84)$. Items were measured on 7-point semantic differentials and addressed behaviour of the group (not goal directed - goal directed), participants initiated discussion on (irrelevant - relevant) issues, participants' contributions were (poorly - well) amplified, participation in the discussion was (unevenly distributed - evenly distributed), ideas expressed in the discussion were (uncritically - critically) examined, participants dealt with issues (unsystematically - systematically), interpersonal relationships among the participants appeared to be (unhealthy - healthy), functions of leadership in the discussion were (poorly - well) served. Gouran et al.'s (1978) original scale contains nine items. We decided to leave out the item on whether positions taken in the discussion were (undocumented - documented) as the Foundation task asks group members to divide money over projects on the basis of personal preferences. Background documentation to the task was constructed in such a way that no specific project was favoured over another. After negatively worded items had been recoded so that higher scores indicated higher scores on the constructs, composite means were calculated for all constructs.

\section{Results}

The data in our study span multiple levels of observation. Individuals are nested within groups, which are part of a specific teaching cohort that is either part of a MSc or MBA program. In the following we first test for the effect of teaching cohort and program. We then report results of each of our research questions. Finally, we turn to a qualitative analysis of our data.

\subsection{Effects of program and cohort}

NFC scores and program (MSc versus MBA) were not independent $\left(\chi^{2}(1)=29.79, \mathrm{p}<.001\right)$. There were relatively more MBA students in the low NFC groups, and, thus, relatively more MSc students in the high NFC groups. We tested the effect of program on the four decision quality variables (change in consensus, satisfaction with the decision process, perceived quality of group recommendations and focus of group member behaviour). T-tests on the effect of program on the dependent variables did not show any significant differences except for satisfaction: mean satisfaction is lower for MBA $(M=3.61, S D=0.54)$ than for MSc students $(M=3.87, S D=0.60, t(166)=3.02, p<.01)$. Because of the non-independence of program and NFC, testing the effect of both variables simultaneously is problematic. Nevertheless, graphs of the effects on each dependent variable seem to indicate a main effect of NFC, as shown in Figure 2.

\section{PLACE FIGURE 2 ABOUT HERE}

There appeared a significant increase in consensus from pre to post, large effect size ( $M_{\text {pre }}=$ $0.27, S D_{\text {pre }}=0.07 ; M_{\text {post }}=0.46, S D_{\text {post }}=0.16 ; M_{\text {change }}=0.20, S D_{\text {change }}=0.14$; Wilks' $\Lambda=.39$, $F(1,39)=60.79 ; p<.001 ; \eta_{\mathrm{p}}{ }^{2}=.61$ ). Interaction effects were not significant (between and 
Cite as: Franco, LA, Rouwette, EAJA, Korzilus, H. Different paths to consensus? The impact of need for closure on model-supported group conflict management. European Journal of Operational Research (2015), http://dx.doi.org/10.1016/j.ejor.2015.06.056

within subjects: program*consensus change, NFC*consensus change, program*NFC*consensus change, nor for their interaction). It is worth noting that power is limited because of the small number of groups and because program and NFC are not independent.

Looking in more depth at the differences between groups for the MSc and MBA programs separately reveals the following. In the MBA groups there were no significant differences in the means of the dependent variables between the low and high NFC groups. In contrast, the MSc groups do reveal differences, in particular with regard to focus of group member behaviour and satisfaction. Effects were significant using both t-tests and Mann-Whitney tests. The high NFC groups have higher scores on these variables than low NFC groups. So, MSc students in the high NFC groups evaluate focus of group member behaviour more positively and experience more satisfaction than the students in the low NFC groups. For perceived quality of recommendations there were no differences.

Our cautious conclusion is that in general the MBA and MSc programs do not differ with regard to the effect of NFC. The main effect of program shows that there are no differences in consensus changes, focus of group behaviour, and perceived quality of recommendations between MBA and MSc, but MSc groups appear more satisfied than MBA groups.

Next we tested the effect of program on conflict management process. The only significant effect is on open discussion: MBA groups spent significantly more time in open discussion than MSc groups $\left(M_{\mathrm{MBA}}=1.23, S D_{\mathrm{MBA}}=0.99 ; M_{\mathrm{MSc}}=0.79, S D_{\mathrm{MSc}}=0.89 ; t(163)=2.98 ; p<\right.$ $.01 ; \eta_{\mathrm{p}}{ }^{2}=.05$ ). For all other variables related to conflict management (conflict, tabulation and capitulation units), the overall differences between high and low NFC groups are repeated in the MSc groups and MBA groups.

As the various teaching cohorts may have an effect on decision quality scores of individuals within each cohort, we employed multilevel modelling following the approach of Hayes (2006). As a first step, the Intraclass Correlation (ICC) was used to test whether multilevel modelling was appropriate for the data (Hayes, 2006, p. 394). ICC represents the amount of variation on individual level as explained by differences in cohort level. Considering a maximum number of 169 individuals, a rough indication (using a $p$-value calculator for correlation coefficients) indicates that ICCs $>.151$ were statistically significant at a significance level $p$ of .05. In case ICC was significant, indicating that multilevel effects might be present, the second step was testing the effect of level-2 variable cohort in a series of four multilevel models. In multilevel modelling effects are considered either fixed or random. A fixed effect means that it has one value for all individuals in the sample, regardless of the cohort to which they belonged. A random effect, on the contrary, does take cohort into account. In the four models variation of fixed and random effects were tested for cohort on the regression intercepts and the regression slopes of the dependent variables. Model 1, the baseline or null model, tests fixed intercepts and fixed slopes, meaning no multilevel effect. Model 2 tests random intercepts and fixed slopes, model 3 fixed intercepts and random slopes and model 4 random intercepts and random slopes. In line with the design of the study, in all four models NFC is having a fixed effect. Models 2 to 4 were compared to the baseline model 1 by means of the -2 Log Likelihood (-2LL) statistic (Hayes, 2006, p. $394)$ to test if model fit improved. The -2LL statistic follows a chi-square $\left(\chi^{2}\right)$ distribution, if the difference in $\chi^{2}$ is larger than 3.84 (6.63) at the expense of 1 degree of freedom than it was a statistically significant improvement at $p=.05$ (.01). In turned out that testing model 4 resulted in estimation problems possibly due to a relatively low number of cases, and is therefore not reported. Table 1 summarises the most important outcomes of the multilevel analyses on cohort. 
Cite as: Franco, LA, Rouwette, EAJA, Korzilus, H. Different paths to consensus? The impact of need for closure on model-supported group conflict management. European Journal of Operational Research (2015), http://dx.doi.org/10.1016/j.ejor.2015.06.056

\section{PLACE TABLE 1 ABOUT HERE}

Table 1 shows that ICC for consensus change and satisfaction with decision process was not significant, consequently there was no multilevel effect of cohort for these variables. For perceived quality of recommendations and focus of group member behaviour ICC was significant but not very large. For these variables model 2, using random intercepts and fixed slopes, showed an improvement in comparison to the baseline model 1. Model 3 resulted in a worse fit than model 1. Inspection of plots (not added) reveals that many cohorts follow the same pattern: relatively low scores on perceived quality of recommendations and focus of group member behaviour, respectively, in the low NFC group and relatively high scores in the high NFC group. The slopes have fairly similar angles, but start on different levels, indicating that the multilevel model with random intercepts and fixed slopes fits the data quite well.

In summary, the tests made clear that there was a limited multilevel effect present in the data. For consensus change and satisfaction with decision process, a multilevel approach did not seem to fit. For perceived quality of recommendations and focus of group member behaviour there was a multilevel effect suggesting that the low NFC groups in the cohorts vary in their mean level of the dependent variable but have fairly similar slopes. The presence of a relative limited multilevel effect in the data and the estimation problems for more complex models made us decide not to conduct additional multilevel analyses with group variables conflict management (conflict, tabulation, capitulation, and open discussion units).

\subsection{Answers to research questions}

1. How does NFC in a group influence conflict management in a model-supported process?

Table 2 summarises descriptive statistics of key study variables and t-tests examining the influence of low versus high NFC groups. The table shows that high NFC groups have a significantly lower number of conflict, capitulation, tabulation, and open discussion units.

\section{PLACE TABLE 2 ABOUT HERE}

On group level controlling for duration, group size, pre-meeting consensus revealed no differences for conflict units, tabulation units, and open discussion units. However, for capitulation units the effect of NFC was no longer significant. (The effect of NFC on capitulation units, without taking into account control variables, was not strong either.)

\section{What is the relationship between conflict management and decision quality?}

Table 3 shows the correlations between conflict management variables and decision quality variables. We first take a look at correlations within each group of variables. It appears that in general there were significant positive and substantial correlations among the conflict management variables (conflict units, capitulation units, tabulation units and open discussion units). There were also significant positive correlations between the decision quality variables satisfaction with the decision process, perceived quality of group recommendations and focus of group member behaviour, but consensus change did not relate to any other decision quality variables. Between the groups of variables, i.e. across the conflict management and decision quality variables, there were two significant but relatively low correlations: a positive correlation (.16) between capitulation units and consensus change and a negative correlation (-.16) between tabulation units and perceived quality of group recommendations.

PLACE TABLE 3 ABOUT HERE 
Cite as: Franco, LA, Rouwette, EAJA, Korzilus, H. Different paths to consensus? The impact of need for closure on model-supported group conflict management. European Journal of Operational Research (2015), http://dx.doi.org/10.1016/j.ejor.2015.06.056

\section{To what extent does conflict management mediate the relation between NFC in a group} and decision quality?

According to the seminal article by Baron and Kenny (1986), a variable functions as a mediator if three conditions are met. First, the independent variable has a significant effect on the (presumed) mediator, in our study NFC on conflict management. Second, there is an effect of the mediator on the dependent variable, here conflict management on decision quality. Third, when both of these effects are controlled, the relation between the independent and dependent variable disappears (full mediation) or grows significantly weaker. The above answer to the first research question shows that the first condition is met. However, Table 3 indicates that the second condition does not apply to our data. There were only two significant correlations between conflict management and decision quality variables. The third condition implies there is a relation between independent and dependent variable which is also absent in our study. Table 2 indicates effects of NFC on two of four decision quality variables; satisfaction and focus of group behaviour were significantly higher in the high versus low NFC groups. We used the PROCESS module in SPSS to test two mediating models in particular: NFC to capitulation units to consensus change, and NFC to tabulation units to perceived quality of recommendations. These analyses corroborated the finding that conflict management does not mediate the relation between NFC and decision quality. NFC appears to have an independent effect on conflict management and on two decision quality variables: satisfaction and focus of group member behaviour.

\subsection{Qualitative analysis of results}

So far we have answered our research questions using quantitative analyses. The analyses presented to this point should constitute the principal source of any inferences that can be drawn from the study. Nevertheless there were certain consistent behavioural patterns in the way high and low NFC groups went about their work that are worth noting. Our observations below are based on an in-depth analysis of four audio-video recordings of interacting groups. Although these observations have not yet been corroborated in any quantitative manner, they may still be useful for shedding more light on the use of models during conflict management in high versus low NFC groups.

Two consistent behavioural patterns were observed between high and low NFC groups. First, the use of a model to inform resource allocation decisions presented a more difficult challenge to high NFC than low NFC groups. High NFC groups struggled to find an effective way to use their models as a basis for their decisions on which projects to fund. This struggle was evidenced by the fact that high NFC groups did not know how to use the information generated from their models in their final choices. Whereas the low NFC groups clearly referred back to the objective maps they had developed at the point of discussing potential resource allocations (e.g. by pointing at particular parts of the map), the high NFC groups tended to discard their maps and opt instead for alternative and simpler means to help them make a decision. This entailed, for instance, undertaking a simple 'back-of-the-envelope' calculation, or using a simple decision rule. One possible explanation for this observed pattern is that the initial disagreements triggered by the model made the possibility of reaching consensus in the remaining time much more difficult for high NFC groups, and so a simpler alternative that could secure consensus faster was preferred.

In addition to retreating to alternative and simpler means to make decisions, high NFC groups exhibited a second behavioural pattern that was in contrast to that by low NFC groups. Whereas low NFC groups appeared to engage in a participative model building process, with facilitation being shared among group members, and with the model being used as a tool for reaching accommodations, the high NFC groups showed the almost the opposite behaviour. Indeed, throughout group discussions in the high NFC groups, control over the 
Cite as: Franco, LA, Rouwette, EAJA, Korzilus, H. Different paths to consensus? The impact of need for closure on model-supported group conflict management. European Journal of Operational Research (2015), http://dx.doi.org/10.1016/j.ejor.2015.06.056

model building process was in the hands of just a few members. These process leaders tended to make the content non-negotiable, particularly when potential conflict emerged. Non-verbal behaviours such as 'grabbing' the flip chart or 'holding the pen', together with actions to control the modelling process by the most vocal group members were much more frequent in high NFC than in low NFC groups.

\section{Discussion and conclusions}

The use of model-based support has been advocated as a powerful mechanism for facilitating group decision making in organisations (e.g. Eden and Ackermann, 2010; Eden and Radford, 1990; Franco and Montibeller, 2010). Whilst significant published empirical research in the model-based group support literature has focussed attention upon providing rich accounts of the deployment and perceived impacts of model-based approaches, two noted shortcomings motivated this research. Firstly, most researchers have been concerned with understanding the role of context in moderating the effects of model-supported group decision making. Attention to examine other contingency factors, such as cognitive aspects, has been relatively sparse. Secondly, scant attention has been paid to examining impacts of such contingency factors on the model-supported group interaction process itself.

This research proposed the need for cognitive closure (NFC) as a relevant contingency factor for the study of model-supported group decision making. Three research questions concerning the potential implications of a heightened NFC for the effectiveness of modelsupported conflict management processes and outcomes were examined through an experimental study. Key results obtained were: (1) groups with a higher, as opposed to lower, disposition on NFC displayed a lower number of conflict, tabulation, and open discussion units; (2) high and low NFC groups achieved similar levels of consensus change but high NFC groups were more satisfied and achieved greater focus on group behaviour than low NFC groups; (3) perceived quality of recommendations did not differ between levels of NFC; and, (4) despite using the same model-based support approach, high versus low NFC groups exhibited different patterns of conflict management processes. The latter result indicates to us that the ability of groups to 'restructure' (DeSanctis and Poole, 1994; Poole et al., 1996) model-based procedures and technology so as to adapt them to their particular requirements or inclinations must be taken into account in studying the impacts of model-based group support approaches.

These results suggest that a heightened NFC may reduce a group's ability to deal with conflict constructively and productively. High NFC groups surface fewer conflicts and manage them in less open ways. Our qualitative analysis shows that high NFC groups use a more controlled, less participative process for building models. They find it difficult to use the resulting models in making their final decision and instead switch to simpler tools. Nevertheless, NFC does not seem to impact consensus change. This apparent puzzle can be resolved if consensus could be understood as 'perceived' instead of 'real' consensus meaning that the tendency of high NFC groups to freeze on a solution would lead members of these groups to quickly settle on a solution that most could live with, while privately still keeping to their initial point of view. In this interpretation high NFC groups would have reached an accommodation rather than a true consensus. However, our measurement of consensus, on the basis of an individual allocation of funds not visible to other members of the group, makes this explanation unlikely. One factor that may help to explain this 'different-processes-but-similar-results' puzzle is the degree of elaboration of information, reflected in the model that the groups build. It is easier to achieve consensus on a general and abstract level; bringing in more detail makes developing a consensus view progressively more difficult. In future research we intend to compare the models of high and low NFC groups with regard to the number of categories of objectives and detail within each category (breadth versus depth, cf. Massey and Wallace, 1996). 
Cite as: Franco, LA, Rouwette, EAJA, Korzilus, H. Different paths to consensus? The impact of need for closure on model-supported group conflict management. European Journal of Operational Research (2015), http://dx.doi.org/10.1016/j.ejor.2015.06.056

Given that high NFC groups follow a 'worse' process, it is striking that high NFC groups are also more satisfied and achieved greater focus. This result is reminiscent of other reported differences between objective and subjective estimates of group performance. Nominal (noninteracting) groups generate more ideas than brainstorming groups, but the latter are more satisfied with their performance (see Stroebe et al., 2010 for an overview of this research tradition). Rouwette et al. (2011) find that after participating in modelling workshops, participants state that they have not learned anything new in the sessions although a comparison of pretest and posttest measurements indicates changes in insight (see also Hodgkinson, 2002). One possible explanation for this finding is that high and low NFC groups were assessing their level of satisfaction and group focus with different decision processes. As suggested by the qualitative analysis, high NFC groups tended to switch to simpler tools to make their decisions, whereas low NFC groups stayed with their models throughout the decision making process. It is thus plausible that high NFC groups were assessing their satisfaction and group focus levels with the (simpler) tools that helped them to achieve speedy consensus.. In addition, in the model-supported environment controlled in this study, the lower levels of confrontiveness that are characteristic for high NFC groups may have resulted in greater focus of group behaviour, particularly in terms of perceptions of goal directedness. However, what makes the picture a bit more complicated in our case is that perceived quality of recommendations, a subjective estimation of process and outcome quality, was not different between high and low NFC groups. This subjective measurement does seem to follow the trend in the objective measurement of consensus. More research is thus needed to shed more light into the issues raised by our study.

Several limitations of this research should be noted. The study used Value-Focused Thinking as the model-supported group approach and NFC as a contingency factor. First, it remains to be determined whether the results are generalisable across model-support group approaches and cognitive factors. Second, our study employed self-facilitated groups. Although the use of model-based support by self-facilitated groups is not uncommon (see, for example, the application of group model building reported in Videira et al., 2012), most model-based group support approaches employ a trained facilitator. On the other hand, the use of selffacilitation avoids the introduction of additional confounding variables (cf.McCardleKeurentjes, 2015). Nevertheless, it remains to be seen if our results can be generalised beyond self-facilitated groups. Third, the study utilized only one type of task. Task variation could produce differences in NFC and model-support effects. Fourth, the study used graduate and postgraduate students as subjects. Additional replications in the field are required before the current results can be generalised. Fifth, the coding procedures employed may have restricted what we can infer about group conflict interaction. Whilst most groups had members with different nationalities, some groups were dominated by British members. Our two coders were non-native English speakers and, therefore, may have been limited in their ability to pick up nuances of the interaction in these groups. Coding reliability was assessed after all groups were coded; additional checks midway would have constituted a better prevention against coder drifting. And finally, as in all studies, we chose a particular conceptualisation of our variables which may steer results in particular direction. We measured NFC on an individual level but used the aggregated group scores in our analyses. In addition, our study looks at conflict management by isolating 30 second units of conflict, tabulation, capitulation and open discussion units. As described before, Sambamurthy and Poole (1992c) aggregate these into four levels of confrontiveness. In our study, confrontiveness levels seemed to hide the clear difference between high and low NFC groups as laid out in Table 2.

Our research has provided some illustration of the value of studying the effects of cognitive factors on model-supported group decision making. The study employed direct behavioural observation and detailed analysis of the group interaction process. Of interest are the 
Cite as: Franco, LA, Rouwette, EAJA, Korzilus, H. Different paths to consensus? The impact of need for closure on model-supported group conflict management. European Journal of Operational Research (2015), http://dx.doi.org/10.1016/j.ejor.2015.06.056

variations in patterns of conflict management processes that were identified. Previous research shows that in unsupported groups, premature group consensus and conformity pressure may elicit a 'groupthink' type of process (Chirumbolo et al., 2004; Park, 2000; Turner and Pratkanis, 1988). In our study, using Value-Focused Thinking, a similar process was observed. Our research demonstrates the value of conducting process-level investigations of model-supported group decision making. Such examinations complement and strengthen insights gained from traditional model-based intervention research that has tended to treat the group interaction process as a black box.

Model building is central to OR practice. The research reported in this paper suggests that when high NFC is present, groups do not always use models as intended and may switch to alternative decision strategies. What are the implications of these findings for the work of the OR practitioner? At a minimum, education and training about NFC can help OR practitioners recognise its signs during model building, so that they can intervene based on established group work practices (e.g. Franco and Montibeller, 2010; Phillips and Phillips, 1993). In addition, preparatory work prior to model-building interventions can reap the most benefits in this respect. Whilst attempting to measure group members' preferences for early closure before engaging in model building would be impractical, managing situational and grouplevel factors so that they are less conducive to a higher need for early closure is possible. For example, it is likely that having enough time and energy, as well as the right physical environment (e.g. low noise levels), will prevent the group from experiencing a high NFC during model building. In addition, the presence of diversity of views and preferences are likely to cause groups to engage in elaborate and deep information processing, thus lowering their need for early closure. However, for these differences to be surfaced during modelling, group members have to able to dissent if needed. This requires OR practitioners working closely with clients to ensure that group members are provided with a climate of 'psychological safety' (Edmondson, 1999), so that they are free to think independently and deliberately during model building. This is particularly crucial when the client is an active participant in the model building process. Although systematic research is lacking, it is reasonable to assume that client's behaviour during modelling will affect the need for closure in the group.

A number of directions for future research can be identified. If, as our findings suggest, the pattern of model use indeed differs between high and low NFC groups, then this has direct implications for the practice of model-based support. A group showing signs of a heightened NFC is likely to resist engaging with the model if they see it as a barrier to reach speedy consensus. The experienced OR facilitator is accustomed to groups trying to move quickly from divergence to convergence in a decision making process. Whether a heightened NFC poses bigger challenges for the experienced facilitator would be a potentially useful avenue to explore. Specifically, identifying how experienced OR facilitators handle dispositional or situational NFC in model-supported group work would generate useful training materials for novice OR facilitators.

One obvious direction for future research would be to replicate our research with a different model-supported group approach, for example, MACBETH (Bana e Costa and Chagas, 2004). Such an approach enables groups to perform quantitative value-based assessments based on qualitative value judgements, which could have provided groups with an alternative form of support to address the task used in this research. Differentiation of the type of analytic capability provided by model-supported group approaches (e.g. qualitative versus qualitative) should permit integration of research findings across different approaches. Another extension for future research would be to examine the effects of other cognitive factors on model-supported group decision-making, for example, need for cognition (Cacioppo and Petty, 1982) and faith in intuition (Dane and Pratt, 2007). The study of these constructs is increasingly being proposed to advance our understanding of the interplay 
Cite as: Franco, LA, Rouwette, EAJA, Korzilus, H. Different paths to consensus? The impact of need for closure on model-supported group conflict management. European Journal of Operational Research (2015), http://dx.doi.org/10.1016/j.ejor.2015.06.056

between structured group decision processes (such as model-supported processes) and those who use it in interaction (Hodgkinson and Clarke, 2007). A third extension would be to replicate the research in a different task context, for example a problem structuring task (e.g. Massey and Wallace, 1996), or in a field setting. Overall, these proposed extensions, together with the methodology adopted here, would help to shed light on the different paths to consensus in model-supported environments.

\section{References}

Ackermann, F. (2012). Problem structuring methods 'in the Dock': Arguing the case for Soft OR. European Journal of Operational Research, 219(3), 652-658.

Ackermann, F., \& Eden, C. (2010). Strategic Options Development and Analysis. In M. Reynolds \& S. Holwell (Eds.), Systems Approaches to Managing Change: A Practical Guide (pp. 135-190). London: Springer.

Ackermann, F., \& Eden, C. (2011). Negotiation in strategy making teams: Group support systems and the process of cognitive change. Group Decision and Negotiation, 20(3), 293-314. doi: DOI: 10.1007/s10726-008-9133-y

Allport, G. W., Vernon, P. E., \& Lindzey, G. (1970). The Study of Values (3rd ed.). Chicago, IL: Riverside.

Alper, S., Tjosvold, D., \& Law, K. S. (2000). Conflict management, efficacy, and performance in organizational teams. Personnel Psychology, 53, 625-642.

Armstrong, S., Cools, E., \& Sadler-Smith, E. (2012). The role of cognitive styles in business and management: Reviewing 40-years of research. International Journal of Management Reviews, 14(3), 238-262.

Armstrong, S. J., \& Priola, V. (2001). Individual differences in cognitve style and their effects on task and social orientations of self-managed work teams. Small Group Research, 32(3), 283-312.

Bana e Costa, C. A., \& Chagas, M. P. (2004). A career choice problem: An example of how to use MACBETH to build a quantitative value model based on qualitative value judgments. European Journal of Operational Research, 153(2), 323-331.

Baron, R. M., \& Kenny, D. A. (1986). The Moderator-Mediator Variable Distinction in Social Psychological Research: Conceptual, Strategic, and Statistical Considerations. Journal of Personality and Social Psychology, 51(6), 1173-1182.

Beaty, J. C., Cleveland, J. N., \& Murphy, K. R. (2001). The relation between personality and contextual performance in strong versus weak situations. Human Performance, 14, 125-148.

Cacioppo, J. T., \& Petty, R. E. (1982). The need for cognition. Journal of Personality and Social Psychology, 42, 116-131.

Checkland, P., \& Poulter, J. (2006). Learning for Action: a short definitive account of Soft Systems Methodology and its use for practitioners, teachers and students. Chichester: Wiley.

Chirumbolo, A., Livi, S., Mannetti, L., Pierro, A., \& Kruglanski, A. W. (2004). Effects of need for closure on creativity in small group interactions. European Journal of Personailty, 18(4), 265-278.

Cohen, J. (1992). A power primer. . Psychological Bulletin, 112(1), 155-159.

Daft, R. L., \& Lengel, R. H. (1986). Organizational Information Requirements, Media Richness, and Structure Design. Management Science, 32(5), 554-571.

Dane, E., \& Pratt, M. (2007). Exploring Intuition and its Role in Managerial Decision Making. Academy of Management Review, 32(1), 33-54.

De Dreu, C. K. W., \& Weingart, L. R. (2003). Task versus relationship conflict, team performance, and team member satisfaction: a meta-analysis. Journal of Applied Psychology, 88(4), 741-749. 
Cite as: Franco, LA, Rouwette, EAJA, Korzilus, H. Different paths to consensus? The impact of need for closure on model-supported group conflict management. European Journal of Operational Research (2015), http://dx.doi.org/10.1016/j.ejor.2015.06.056

De Grada, E., Kruglanski, A. W., Mannetti, L., \& Pierro, A. (1999). Motivated cognition and group interaction: Need for closure affects the contents and processes of collective negotiations. Journal of Experimental Social Psychology, 35, 346-365.

de Kwaadsteniet, E. W., van Dijk, E., Wit, A., \& de Cremer, D. (2006). Social dilemmas as strong versus weak situations: Social value orientations and tacit coordination under resource size uncertainty. Journal of Experimental Social Psychology, 42(4), 509516.

De Wit, F. R., Greer, L. L., \& Jehn, K. A. (2012). The paradox of intragroup conflict: a metaanalysis. Journal of Applied Psychology, 97(2), 360.

DeSanctis, G., \& Gallupe, R. B. (1987). A Foundation for the Study of Group Decision Support Systems. Management Science, 33(5), 589-609.

DeSanctis, G., \& Poole, M. S. (1994). Capturing the Complexity in Advanced Technology Use: adaptive structuration theory. Organization Science, 5(2), 121-147.

Eden, C. (1988). Cognitive Mapping: a review. European Journal of Operational Research, 36(1), 1-13.

Eden, C. (1995). On Evaluating the Performance of "Wide-band" GDSS's. European Journal of Operational Research, 81(2), 302-311.

Eden, C., \& Ackermann, F. (2010). Decision Making in Groups: Theory and practice. In P. C. Nutt \& D. C. Wilson (Eds.), Handbook of Decision Making (pp. 231-272). Chichester: Wiley.

Eden, C., \& Ackermann, F. (2013). Problem structuring: On the nature of, and reaching agreement about, goals. EURO Journal on Decision Processes, 1(1-2), 7-28.

Eden, C., \& Radford, J. (1990). Tackling Strategic Problems: The role of group decision support. London: Sage.

Edmondson, A. C. (1999). Psychological safety and learning behaviour in work teams. Administrative Science Quarterly, 44(2), 350-383.

Eisenhardt, K. M., Kahwajy, J. L., \& Bourgeois, L. J. I. (1997). How management teams can have a good fight. Harvard Business Review, 75(4), 77-85.

Fisher, R., \& Ury, W. (1991). Getting to Yes (2nd ed.). New York: Penguin.

Fleiss, J. L. (1981). Statistical methods for rates and proportions (2nd ed.). New York: John Wiley.

Folger, J. P., Poole, M. S., \& Stutman, R. (1996). Working Through Conflict: Strategies for relationships, groups, and organizations (3rd ed.): Longman Pub Group.

Franco, L. A. (2009). Problem structuring methods as intervention tools: Reflections from their use with multi-organizational teams. OMEGA: The International Journal of Management Science, 37(1), 193-203.

Franco, L. A., \& Lord, E. (2011). Understanding multi-methodology: Evaluating the perceived impact of mixing methods for group budgetary decisions. OMEGA: The International Journal of Management Science, 39(3), 362-372.

Franco, L. A., \& Meadows, M. (2007). Exploring new directions in problem structuring methods research: On the role of cognitive style. Journal of the Operational Research Society, 58(12), 1621-1629.

Franco, L. A., \& Montibeller, G. (2010). Facilitated modelling in operational research (Invited Review). European Journal of Operational Research, 205(3), 489-500.

Friend, J., \& Hickling, A. (2005). Planning Under Pressure: The Strategic Choice Approach (3rd ed.). Abingdon, Oxon: Routledge.

Gardner, W. (1987). The mind's new science: A history of the cognitive revolution New York: Basic Books.

Garvin, D. A., \& Roberto, M. A. (2001). What you don;t know about making decisions. Harvard Business Review, 79(8), 108-116.

Gersick, C. J. G. (1988). Time and Transition in Work Teams: towards a new model of group development. Academy of Management Journal, 31(1), 9-41.

Gersick, C. J. G. (1989). Marking Time: predictable transitions in works groups. Academy of Management Journal, 32(2), 274-309. 
Cite as: Franco, LA, Rouwette, EAJA, Korzilus, H. Different paths to consensus? The impact of need for closure on model-supported group conflict management. European Journal of Operational Research (2015), http://dx.doi.org/10.1016/j.ejor.2015.06.056

Gouran, D. S., Brown, C., \& Henry, D. R. (1978). Behavioral correlates of perceptions of quality in decision-making discussions. Communication monographs, 45(1), 51 - 63.

Green, S. G., \& Taber, T. D. (1980). Effects of three social decision schemes on decision group-process. Organizational Behavior and Human Performance, 25(1), 97-106.

Hamalainen, R. P., Luoma, J., \& Saarinen, E. (2013). On the importance of behavioral operational research: The case of understanding and communicating about dynamic systems. European Journal of Operational Research, 228(3), 623-634.

Hardin, C., \& Higgins, E. (1996). Shared reality: How social verification makes the subjective objective. In R. Sorrentino \& E. Higgins (Eds.), Handbook of motivation and cognition (Vol. 3) (pp. 28-84). New York: Guilford Press.

Hare, A. P. (1981). Group Size. American Behavioral Science(24), 695-708.

Hayes, A. F. (2006). A primer on multilevel modeling. Human Communication Research, 32(4), 385-410.

Hodgkinson, G. P. (2002). Comparing managers' mental models of competition: why selfreport measures of belief similarity won't do. Organization Studies, 23(1), 63-72.

Hodgkinson, G. P., \& Clarke, I. (2007). Exploring the cognitive significance of organizational strategizing: A dual process framework and research agenda. Human Relations, 60(1), 243-255.

Jackson, S. E., Joshi, A., \& Erhardt, N. L. (2003). Recent research on team organizational diversity: SWOT analysis and implications. Journal of Management, 29, 801-830.

Janis, I. L. (1972). Victims of Groupthink. Boston, MA: Houghton-Mifflin.

Jehn, K. A., Northcraft, G. B., \& Neale, M. A. (1999). Why differences make a difference: A field study of diversity, conflict, and performance in workgroups. Admnistrative Science Quarterly, 44(741-763).

Jessop, L., \& Valacich, J. (1993). Group Support Systems: new directions. New York: MacMillan.

Keeney, R. L. (1992). Value-Focused Thinking: a path to creative decision-making Cambridge, MA: Harvard University Press.

Keeney, R. L. (1996). Value-focused thinking: Identifying decision opportunities and creating alternatives. European Journal of Operational Research, 92(3), 537-549.

Keeney, R. L. (2012). Value-Focused Brainstorming. Decision Analysis, 9(4), 303-313.

Kruglanski, A. W. (1989). Lay Epistemics and Human Knowledge: Cognitive and motivational bases. New York: Plenum Press.

Kruglanski, A. W. (1990). Motivations for Judging and Knowing: Implications for causal attribution. In E. Higgins \& R. Sorrentino (Eds.), The Handbook of Motivation and Cognition: foundation of social behavior (Vol 2) (pp. 333-368). New York: Guilford Press.

Kruglanski, A. W. (2004). The psychology of closed-mindedness. New York: Psychology Press.

Kruglanski, A. W., Dechesne, M., Orehek, E., \& Pierro, A. (2009). Three decades of lay epistemics: The why, how, and who of knowledge formation. European Review of Social Psychology, 201(1), 146-191.

Kruglanski, A. W., Pierro, A., Mannetti, L., \& De Grada, E. (2006). Groups as Epistemic Providers: Need for Closure and the Unfolding of Group-Centrism. Psychological Review, 113(1), 84-100.

Kruglanski, A. W., \& Webster, D. M. (1991). Group members' reactions to opinion deviates and conformists at varying degrees of proximity to decision deadline and of environmental noise. . Journal of Personality and Social Psychology, 61, 212-225.

Kruglanski, A. W., \& Webster, D. M. (1996). Motivated closing of the mind: 'Seizing”' and “freezing'. Psychological Review, 103(2), 263-283.

Kruglanski, A. W., Webster, D. M., \& Klem, A. (1993). Motivated resistance and openness to persuasion in the presence or absence of prior information. Journal of Personality and Social Psychology, 65(5), 861-876. 
Cite as: Franco, LA, Rouwette, EAJA, Korzilus, H. Different paths to consensus? The impact of need for closure on model-supported group conflict management. European Journal of Operational Research (2015), http://dx.doi.org/10.1016/j.ejor.2015.06.056

Mannetti, L., Pierro, A., Kruglanski, A., Taris, T., \& Bezinovic, P. (2002). A cross-cultural study of the Need for Cognitive Closure Scale: Comparing its structure in Croatia, Italy, USA and The Netherlands. British Journal of Social Psychology, 41(1), 139156.

Massey, A. P., \& Wallace, W. A. (1996). Understanding and Facilitating Group Problem Structuring and Formulation: mental representations, interaction, and representation aids. Decision Support Systems, 17, 253-274.

McCardle-Keurentjes, M. M. F. (2015). Facilitated modelling and hidden profiles: An experimental evaluation of Group Model Building. Unpublished $\mathrm{PhD}$ thesis, Nijmegen: Radboud University.

Mingers, J. (2011). Soft OR comes of age -But not everywhere! OMEGA: The International Journal of Management Science, 39(6), 729-741.

Mitroff, I. L., \& Ernshoff, J. R. (1974). On Systemic Problem Solving and the Error of the Third Kind. Behavioral science, 19, 383-393.

Montibeller, G., Franco, L. A., Lord, E., \& Iglesias, A. (2009). Structuring Resource Allocation Decisions: a framework for building multi-criteria portfolio models with area-grouped projects. European Journal of Operational Research, 199(3), 846-856. doi: 10.1016/j.ejor.2009.01.054

Morton, A., Ackermann, F., \& Belton, V. (2003). Technology-driven and model-driven approaches to group decision support: Focus, research philosophy and key concepts. European Journal of Information Systems, 12(2), 110-126.

Nijstad, B. A., \& De Dreu, C. K. (2012). Motivated information processing in organizational teams: Progress, puzzles, and prospects. Research in Organizational Behavior, 32, 87-111.

Nutt, P. C. (2002). Why Decisions Fail? Avoiding the blunders and traps that lead to debacles. San Francisco, CA: Berrett-Koehler Publishers.

Nutt, P. C. (2008). Investigating the success of decision making processes. Journal of Management Studies, 45(2), 425-455.

Park, W. (2000). A comprehensive empirical investigation of the relationships among variables of the groupthink model. Journal of Organizational Behavior, 21(8), 873887.

Pelled, L. H., Eisenhardt, K. M., \& Xin, K. R. (1999). Exploring the black box: An analysis of work group diversity, conflict, and performance. Admnistrative Science Quarterly, 44, $1-28$.

Phillips, L. (2007). Decision Conferencing. In W. Edwards, R. Miles Jr, \& D. von Winterfeldt (Eds.), Advances in Decision Analysis: from foundations to applications (pp. 375-399). New York: Cambridge University Press.

Phillips, L., \& Phillips, M. (1993). Facilitated Work Groups: theory and practice. Journal of Operational Research Society, 44(6), 533-549.

Pierro, A., Mannetti, L., De Grada, E., Livi, S., \& Kruglanski, A. W. (2003). Autocracy bias in informal groups under need for closure. Personality and Social Psychology Bulletin, 29(3), 405-417.

Poole, M. S. (1983). Decision Development in Small Groups II: a study of multiple sequences in decision making. Communication Monographs, 50(3), 206-232.

Poole, M. S., \& Dobosh, M. (2010). Exploring Conflict Management Processes in Jury Deliberations Through Interaction Analysis. Small Group Research, 41(4), 408-426.

Poole, M. S., \& Roth, J. (1989). Decision Development in Small Groups IV: a typology of group decision paths. Human Communication Research, 15(3), 323-356.

Poole, M. S., Seibold, D. R., \& McPhee, R. D. (1996). The Structuration of Group Decisions. In R. Y. Hirokawa \& M. S. Poole (Eds.), Communication and Group Decision Making (2nd ed., pp. 114-146). Thousand Oaks, CA: Sage.

Richardson, G. P., \& Andersen, D. F. (1995). Teamwork in group model building. System Dynamics Review, 11(2), 113-137. 
Cite as: Franco, LA, Rouwette, EAJA, Korzilus, H. Different paths to consensus? The impact of need for closure on model-supported group conflict management. European Journal of Operational Research (2015), http://dx.doi.org/10.1016/j.ejor.2015.06.056

Roets, A., \& Van Hiel, A. (2007). Separating ability from need: clarifying the dimensional structure of the need for closure scale. Personality and Social Psychology Bulletin, 33(2), 266-280.

Rouwette, E. A. J. A., Korzilius, H., Vennix, J. A. M., \& Jacobs, E. (2011). Modeling as persuasion: The impact of group model building on attitudes and behavior. System Dynamics Review, 27(1), 1-21.

Sambamurthy, V., \& Poole, M. S. (1992a). The Effects of Variations in Capability of GDSS Designs on Management of Cognitive Conflict in Groups. MIS Quarterly, 3(3), 224251.

Sambamurthy, V., \& Poole, M. S. (1992c). The effects of variations in GDSS capabilities on management of cognitive conflict in groups. Information Systems Research, 3, 224251.

Schilling, M. S., Oeser, N., \& Schaub, C. (2007). How Effective are Decision Analyses? Assessing Decision Process and Group Alignment Effects. Decision Analysis, 4(4), 227-242.

Shaw, D., Ackermann, F., \& Eden, C. (2003). Approaches to sharing knowledge in group problem structuring. Journal of the Operational Research Society, 54(9), 936-948.

Snyder, M., \& Ickes, W. (1985). Personality and social behavior. In G. Lindzey \& E. A. Aronson (Eds.), Handbook of social psychology (Vol. 2, pp. 883-925). New York: Random House.

Spillman, B., Spillman, R., \& Bezdek, J. A. (1980). A Fuzzy Analysis of Consensus in Small Groups. In P. P. Wang \& S. K. Chang (Eds.), Fuzzy Set: theory and application to policy analysis and information systems (pp. 291-308). New York: Plenum.

Stroebe, W., Nijstad, B. A., \& Rietzschel, E. (2010). Beyond productivity loss in brainstorming groups: the evolution of a question. Advances in Experimental Social Psychology, 43, 157-203.

Thomas, E. G., \& Fink, E. F. (1963). Effects of Group Size. Psychological Bulletin, 60(4), 371-384.

Turner, M. E., \& Pratkanis, A. R. (1988). Twenty-five years of groupthink theory and research: Lessons from the evaluation of a theory. Organizational Behavior and Human Decision Processes, 73(2-3), 105-115.

van Knippenberg, D., de Dreu, K. W., \& Homan, A. C. (2004). Work group diversity and group performance: An integrative model and research agenda. Journal of Applied Psychology, 89, 1008-1022.

Vennix, J. A. M. (1996). Group Model Building: Facilitating team learning using System Dynamics. Chichester: Wiley.

Vennix, J. A. M. (1999). Group model-building: Tackling messy problems. System Dynamics Review, 15(4), 379-401.

Videira, N., Lopes, R., Antunes, P., Santos, R., \& Casanova, J. L. (2012). Mapping maritime sustainability issues with stakeholder groups. Systems Research and Behavioral Science, 29(6), 596-619.

Volkema, R. J., \& Gorman, R. H. (1998). The Influence of cognitive -based group composition on decision-making process and outcome Journal of Management Studies, 35(1), 105-121.

Watson, R. T., DeSanctis, G., \& Poole, M. S. (1988). Using a GDSS to Facilitate Group Consensus: some intended and unintended consequences. MIS Quarterly, 12(4), 463478.

Watson, W., Sharp, W., \& Michaelsen, L. K. (1991). Member competence, group interaction and group decision making: A longitudinal study. Journal of Applied Psychology, 76(6), 803-809.

Webster, D. M., \& Kruglanski, A. W. (1994). Individual Differences in Need for Cognitive Closure. Journal of Personality and Social Psychology, 67(6), 1049-1062.

White, L. (2009). Understanding Problem Structuring Methods Interventions. European Journal of Operational Research, 99(3), 823-833. 
Cite as: Franco, LA, Rouwette, EAJA, Korzilus, H. Different paths to consensus? The impact of need for closure on model-supported group conflict management. European Journal of Operational Research (2015), http://dx.doi.org/10.1016/j.ejor.2015.06.056

Williams, K. Y., \& O'Reilly, C. A. (1998). Demography and diversity in organizations: A review of 40 years of research. Research in Organizational Behavior, 20, 77-140. 
Cite as: Franco, LA, Rouwette, EAJA, Korzilus, H. Different paths to consensus? The impact of need for closure on model-supported group conflict management. European Journal of Operational Research (2015), http://dx.doi.org/10.1016/j.ejor.2015.06.056

Figure 1: Conceptual model

\begin{tabular}{|c|c|c|}
\hline Need for closure & Conflict & Decision quality \\
\hline
\end{tabular}


Cite as: Franco, LA, Rouwette, EAJA, Korzilus, H. Different paths to consensus? The impact of need for closure on model-supported group conflict management. European Journal of Operational Research (2015), http://dx.doi.org/10.1016/j.ejor.2015.06.056

Figure 2: Effects of NFC and program on decision quality

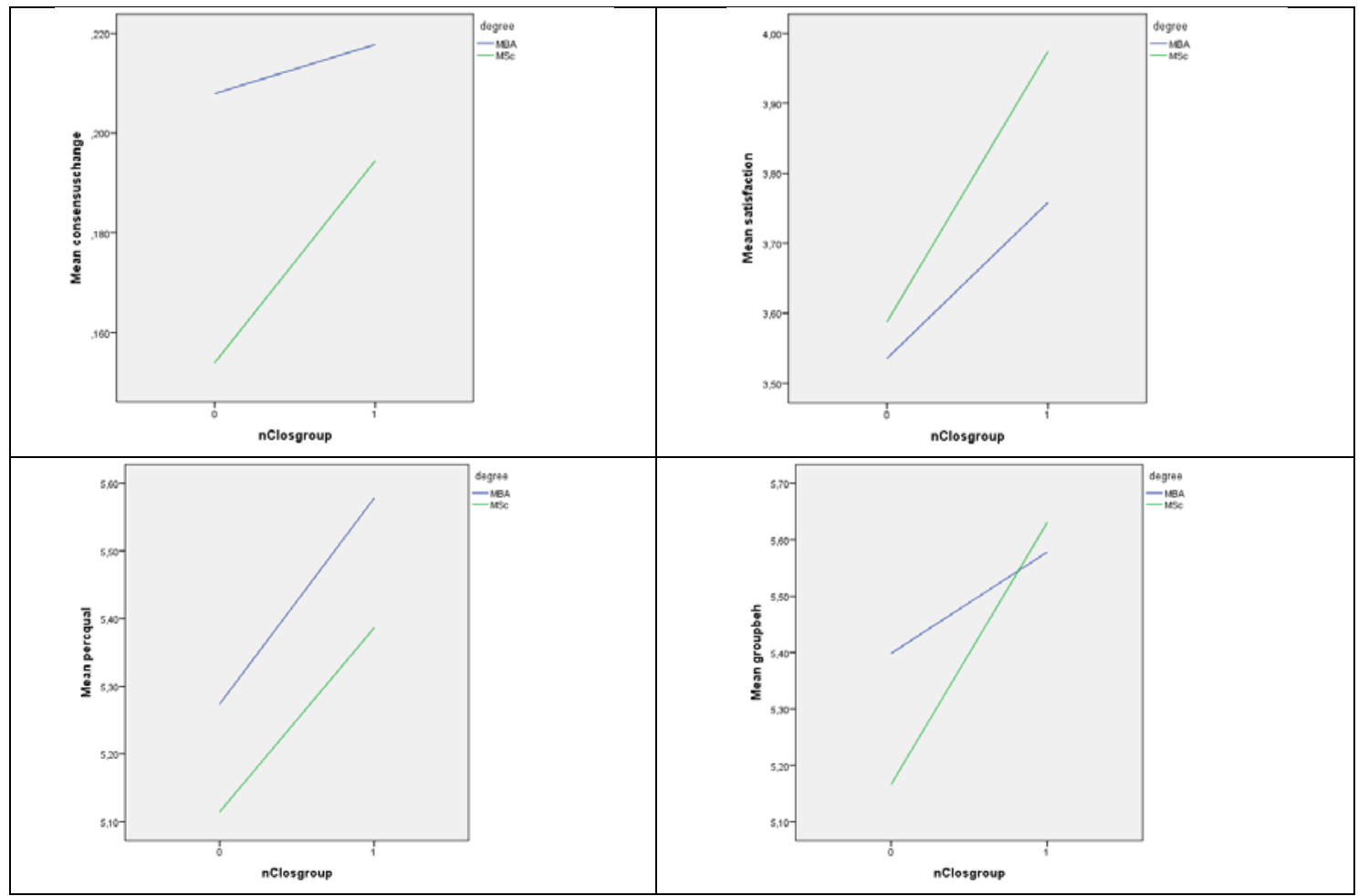

Note. nClosgroup $=$ NFC, $0=$ low, $1=$ high . 
Cite as: Franco, LA, Rouwette, EAJA, Korzilus, H. Different paths to consensus? The impact of need for closure on model-supported group conflict management. European Journal of Operational Research (2015), http://dx.doi.org/10.1016/j.ejor.2015.06.056

Table 1: Multilevel modelling outcomes for cohort

\begin{tabular}{lcclllc}
\hline Dependent variable & ICC & $\begin{array}{l}\text { Model 1 } \\
-2 \mathrm{LL} \\
(d f=3)\end{array}$ & $\begin{array}{l}\text { Model 2 } \\
-2 \mathrm{LL} \\
(d f=4)\end{array}$ & $\begin{array}{l}\text { Model } \\
1 \text { vs. 2 } \\
\Delta \chi 2\end{array}$ & $\begin{array}{l}\text { Model 3 } \\
-2 \mathrm{LL} \\
(d f=4)\end{array}$ & $\begin{array}{l}\text { Model } \\
1 \text { vs. 3 }\end{array}$ \\
\hline $\begin{array}{l}\text { Consensus change } \\
\begin{array}{l}\text { Satisfaction with } \\
\text { decision process }\end{array}\end{array}$ & .06 & & & & & \\
$\begin{array}{l}\text { Perceived quality of } \\
\text { recommendations }\end{array}$ & $.15^{*}$ & 409.65 & 394.08 & $15.57^{* *}$ & 414.04 & -4.39 \\
$\begin{array}{l}\text { Focus of group } \\
\text { member behaviour }\end{array}$ & $.15^{*}$ & 386.21 & 371.06 & $15.15^{* *}$ & 392.21 & -6.01 \\
\hline
\end{tabular}

Note. $\quad$ Model 1: baseline, fixed intercepts, fixed slopes; Model 2: random intercepts, fixed slopes; Model 3: fixed intercepts, random slopes. Need for cognition is fixed in all models.

ICC is intraclass correlation; -2LL is -2 Log Likelihood (see text). A positive (negative) number in the Model comparisons (columns 5 and 7) indicates an increase (decrease) in model fit. ${ }^{*} p<.05,{ }^{* *} p<.01$ 
Cite as: Franco, LA, Rouwette, EAJA, Korzilus, H. Different paths to consensus? The impact of need for closure on model-supported group conflict management. European Journal of Operational Research (2015), http://dx.doi.org/10.1016/j.ejor.2015.06.056

Table 2: Descriptive and inferential statistics of key study variables

\begin{tabular}{|c|c|c|c|c|c|c|}
\hline Variables & Low NFC & High NFC & $\mathbf{t}$ & df & $\mathbf{p}$ & Cohen's d \\
\hline Group level & $n=19$ & $n=21$ & & & & \\
\hline Group size & $4.63(0.68)$ & $4.52(0.60)$ & 0.53 & 38 & .60 & 0.17 \\
\hline Duration of group meeting & 62.55 (2.63) & $58.68(4.59)$ & $3.22^{a}$ & 32.43 & $.002 * *$ & 1.02 \\
\hline $\begin{array}{l}\text { Level of existing conflict } \\
\text { (pre-meeting consensus) }\end{array}$ & $0.28(0.07)$ & $0.26(0.08)$ & 0.72 & 38 & .47 & 0.27 \\
\hline Post-meeting consensus & $0.46(0.16)$ & $0.46(0.17)$ & 0.02 & 38 & .98 & 0.00 \\
\hline Conflict units & $11.11(10.01)$ & $5.14(4.98)$ & $2.35^{a}$ & 25.81 & $.027 *$ & 0.77 \\
\hline Capitulation units & $1.26(1.24)$ & $0.62(0.59)$ & $2.06^{a}$ & 25.17 & $.050 *$ & 0.67 \\
\hline Tabulation units & $1.47(1.12)$ & $0.67(0.80)$ & 2.64 & 38 & $.012 *$ & 0.83 \\
\hline Open discussion units & $7.89(9.34)$ & $2.81(4.29)$ & $2.18^{a}$ & 24.70 & $.039 *$ & 0.71 \\
\hline Individual level & $n=82$ & $n=86$ & & & & \\
\hline Consensus change & $0.19(0.16)$ & $0.20(0.12)$ & $0.43^{a}$ & 145.12 & .67 & 0.07 \\
\hline $\begin{array}{l}\text { Satisfaction with decision } \\
\text { process }\end{array}$ & $3.55(0.56)$ & $3.90(0.56)$ & 4.04 & 162 & $\begin{array}{l}<.001 \\
* * *\end{array}$ & 0.63 \\
\hline $\begin{array}{l}\text { Perceived quality of } \\
\text { recommendations }\end{array}$ & $5.22(0.86)$ & $5.46(0.78)$ & 1.83 & 162 & .070 & 0.29 \\
\hline $\begin{array}{l}\text { Focus of group member } \\
\text { behaviour }\end{array}$ & $5.33(0.80)$ & $5.62(0.74)$ & 2.43 & 162 & $.016^{*}$ & 0.38 \\
\hline \multicolumn{7}{|c|}{$\begin{array}{l}\text { Note. Duration of group meeting is measured in minutes. Satisfaction with decision process is } \\
\text { measured on a 5-point scale. Perceived quality of recommendations and focus of group member } \\
\text { behaviour are measured on 7-point scales. Cells in Column } 2 \text { and } 3 \text { depict mean and (standard } \\
\text { deviation). }{ }^{a} \text { Levene's test was significant, therefore t-tests for unequal variances are reported. }{ }^{*} p< \\
.05,{ }^{* *} p<.01,{ }^{* * *} p<.001 \text {. Cohen's d indicate effect sizes: } .20 \text { small, } .50 \text { medium, and } .80 \text { large } \\
\text { (Cohen, 1992). }\end{array}$} \\
\hline
\end{tabular}


Cite as: Franco, LA, Rouwette, EAJA, Korzilus, H. Different paths to consensus? The impact of need for closure on model-supported group conflict management. European Journal of Operational Research (2015), http://dx.doi.org/10.1016/j.ejor.2015.06.056

Table 3: Correlations between conflict management (1-4) and decision quality variables (5-8)

\begin{tabular}{llllllll}
\hline & 1 & 2 & 3 & 4 & 5 & 6 & 7 \\
\hline 1 Conflict units & & & & & & & \\
2 Capitulation units & $.64^{* * *}$ & & & & & \\
3. Tabulation units & $.72^{* * *}$ & $.34^{* * *}$ & & & & & \\
4 Open discussion units & $.77^{* * *}$ & $.62^{* * *}$ & $.66^{* * *}$ & & & & \\
5 Consensus change & .04 & $.16^{*}$ & -.00 & -.00 & & & \\
6 Satisfaction with decision process & -.01 & .05 & -.15 & -.06 & .13 & & \\
7 Perceived quality of recommendations & -.08 & -.03 & $-.16^{*}$ & -.03 & .10 & $.24^{* *}$ & \\
8 Focus of group member behaviour & -.08 & -.03 & -.12 & -.01 & .09 & $.33^{* * *}$ & $.76^{* * *}$ \\
\hline
\end{tabular}

Note. $\quad$ Ns vary between164 and 165 